\title{
Validity of the Emotion Regulation of Self Scale among Runners
}

\author{
Andrew M. Lane, Christopher J. Beedie, Damian M. Stanley, \\ Tracey J. Devonport \\ School of Sport Performing Arts and Leisure, University of Wolverhampton, Wolverhampton, UK. \\ Email: A.M.Lane2@wlv.ac.uk

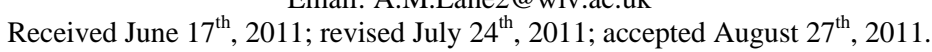

\begin{abstract}
The Emotion Regulation of Other and Self scale (EROS: Niven, Totterdell, Stride, \& Holman, 2011) was originally designed to assess strategies used to increase both pleasant and unpleasant emotions in a range of situations and over a 4 week period. The aim of the present study was to cross-validate the scale in a specific situation and over a shorter timeframe, specifically in sport competition. Participants $(N=700)$ completed the EROS scale whilst recalling strategies within an hour of competing in a running race of personal importance. Confirmatory factor analysis results indicate some support for the integrity of a two-factor model. Factor loadings indicated limitations with items designed to assess behavioral strategies to increase pleasant emotions and also unpleasant emotions. After removing these weak-loading items and reanalyzing data, results indicated acceptable fit indices. We suggest the scale has some utility in running but recommend that future research should develop domainspecific items.
\end{abstract}

Keywords: Mood, Affect, Psychological Skills, Self-Regulation, Measurement

\section{Introduction}

Emotions have a pervasive effect on human functioning (Baumeister, Vohs, DeWall, \& Zhang, 2007; Nesse, 1990). Evidence indicates significant relationships between emotional states and performance in different areas of application including work (Wallace, Edwards, Shull, \& Finch, 2009), the military (Tenenbaum, Edmonds, \& Eccles, 2008 2008) and sports competition (Beedie, Terry, \& Lane, 2000; Jokela \& Hanin, 1999; Lazarus, 2000). Research has demonstrated that individuals who report positive ${ }^{1}$ emotions before performing are likely to have regulated them in the period before competition (Pensgaard \& Duda, 2003; Robazza, Pellizzari, Bertollo, \& Hanin, 2008; Totterdell \& Leach, 2001). Given the relationship between emotions and performance, it is not surprising that practitioners have sought to examine not only the emotions experienced by athletes, but also the regulatory processes related to them (Gould \& Maynard, 2009). Emotion regulation is defined as a set of automatic and controlled processes involved in the initiation, maintenance, and modification of the occurrence, intensity, and duration of feeling states (Gross, 2007; Gross \& John, 2003). One way of measuring emotion regulation strategies is to use questionnaires or inventories, but the utility of an instrument will depend fundamentally upon its psychometric properties. If validity has not been demonstrated,

${ }^{1}$ There are substantial semantic issues related to the use of terms such as 'positive', 'negative', 'pleasant', 'unpleasant', 'helpful', 'unhelpful', 'functional' and 'dysfunctional' in relation to emotions. The idea that, because an emotion such as depression or anxiety is usually subjectively experienced as unpleasant, it is at the same time therefore 'negative', 'unhelpful' or 'dysfunctional' is questioned by many authors, especially those examining the phenomena from a psycho-evolutionary angle (e.g., Nesse, 1990). To remain consistent with previous research in sport, we use terms such as 'negative' and 'unpleasant' to describe emotions such as anger, anxiety, sadness, and depression, and terms such as 'positive' or 'pleasant' to describe emotions such as happiness, relief, hope and excitement. Some greater clarity on these issues however, although beyond the scope of the present paper, is long overdue. it is hazardous to accept and apply data derived from such measures (Cronbach \& Meehl, 1955; Schutz \& Gessaroli, 1993).

Psychometric assessment of emotion regulation tends to focus on the conscious use of strategies (Parkinson \& Totterdell, 1999; Thayer, Newman, \& McClain, 1994). Conscious regulatory acts involve the agent identifying the desirable affective state, and then engaging in some kind of action, such as thoughts or behaviors, to reduce the difference between their current and preferred state (Carver, 2004; Cervone, Mor, Orom, Shadel, \& Scott, 2004). Researchers typically ask participants to identify emotion regulation strategies used over a given period of time (Augustine \& Hemenover, 2008; Parkinson \& Totterdell, 1999; Thayer et al., 1994). In their recent meta-analysis of emotion regulation strategies, Augustine and Hemenover noted there are at least 300 possible strategies, and proposed that a broad cognitive versus behavioral distinction provides the most acceptable classification. Examples of cognitive strategies include thinking positive or hopeful thoughts, whereas behavioral strategies comprise actions such as listening to music and intentionally doing something pleasant. Clearly, attempting to include all 300 strategies would create a lengthy measure, especially as brevity is particularly important for researchers wishing to assess emotion regulation strategies in ecologically valid situations such as before athletic competition or giving a public performance (Davies, Lane, \& Devonport, 2010; Lane, 2007).

A great deal of research has investigated the argument that individuals generally seek to increase pleasant and to reduce unpleasant emotions (Augustine \& Hemenover, 2008). In this context it has been proposed that emotional well-being is indexed by the ratio of pleasant to unpleasant emotions (Larsen, 2009). Whilst this approach to examining emotion regulation is appropriate in the long-term, it does not always apply in the short-term where different emotion regulatory motives might apply; although Larsen argued that the primary focus of emotion regulation research should be to examine strategies to en- 
hance pleasant emotions, there are a number of different situations when this model might not apply (Martin, 2001). For example, an individual is likely to accept feeling sad at a funeral but would be less likely to accept feeling sad at a birthday party and would likely engage in efforts to regulate such feelings. Similarly, before an important task (e.g., a surgeon performing an operation, an athlete trying to win an Olympic medal, or a manager giving a presentation to a board of directors), an individual could expect to feel a wide range of pleasant and unpleasant feelings, either of which may facilitate performance. In fact, recent research has demonstrated that individuals increase unpleasant emotions as well as pleasant emotions for such instrumental purposes (Tamir, 2009; Tamir, Chiu, \& Gross, 2007; Tamir, Mitchell, \& Gross, 2008). This suggests that if an individual believes that increasing unpleasant emotions will evoke action tendencies that help goal pursuit, then the individual could be motivated to regulate their emotions in that direction. From an evolutionary perspective, it is proposed that emotions such as anxiety and anger function to inform the individual of impending loss or danger unless action is taken (Nesse, 1990). Indeed, at least two meta-analytic studies have demonstrated that emotions such as anger and anxiety are sometimes associated with successful sport performance (Beedie et al., 2000; Jokela \& Hanin, 1999). Further, qualitative research has demonstrated that athletes develop meta-beliefs that emotions such as anger and anxiety can be functional both before and during competition, as these emotions signal that goal attainment is threatened (Hanin, 2003). A scale to assess the motivation underlying attempts to increase unpleasant emotions would help elucidate this phenomenon.

Based on the theoretical framework developed by Niven, Totterdell, and Holman (2009), researchers have recently developed a 12-item scale to assess emotion regulation strategies intended to both improve and worsen emotions (Emotion Regulation of Self and Others; EROS, (Niven et al., 2011). The term 'improving emotions' refers to strategies aimed at increasing pleasant emotions whereas the term 'worsening emotions' refers to strategies aimed at increasing unpleasant emotions. Given findings that suggest that emotions described as 'unpleasant' can associate with good performance (Beedie et al., 2000; Jokela \& Hanin, 1999), as well as evidence that athletes often attempt to increase the intensity of these unpleasant emotions (Hanin, 2003), it is suggested that the terms 'worsening' and 'improving' are misleading. We suggest that they should be replaced and propose using the labels 'increasing pleasant emotions' and 'increasing unpleasant emotions'.

Niven et al. (2011) demonstrated factorial validity of the EROS scale among two independent samples using confirmatory factor analysis. It should be noted that Niven et al. asked participants to report usage of emotion regulation strategies over the previous 4 weeks and so people are likely to have had an opportunity to engage in a range of different tasks. Recent research has found that the scale has utility across a range of different areas of application. Niven and Holman (2009) demonstrated that strategies used to regulate one's own emotions associated with general well-being among a heterogeneous sample of over 500 participants from the general public. Dhingra, Totterdell, Tantam, and Taylor (2010) found that strategies used to increase unpleasant emotions associated with increased likelihood of engaging in self-harm in a clinical setting.

Given the notion that validation of psychometric measures is regarded as an ongoing process (Cronbach \& Meehl, 1955; Schutz \& Gessaroli, 1993) we sought to cross-validate the measure for use in sport. Sport and exercise psychology is an area of application in which the tradition is to develop a situation-specific measure. This tradition is based on the argument that measures developed in one area transfer poorly to sport and exercise with the result being a large body of sport-specific scales (Duda, 1998). Therefore, we argue that cross validating a measure to sport represents a rigorous test of the validity of the scale.

\section{Methods}

\section{Participants}

The sample of volunteer runners was heterogeneous $(N=700$; male, $n=338$, age, $M=37.98$ years, $S D=9.9$; female, $n=360$, age, $M=36.02$ years, $S D=8.54$; 2 did not report gender) in terms of previous experience ranging from recreational to international ( $n=369$, club $n=182$, regional $n=82$, national $n=$ 44 , international $n=19$ ). Runners competed at distances ranging from $5 \mathrm{~km}$ to a marathon.

\section{Measures}

The emotion regulation scale consists of 12 items designed to assess strategies intended to increase pleasant emotions and strategies intended to increase unpleasant emotions (see Table 1 for examples of items). Participants are instructed to rate the frequency of usage, rather than to evaluate whether each strategy was effective. Participants rate items on a 5-point scale ( $1=$ not at all, 5 = a great deal). In the present study, participants reported the strategies they used during the hour before competition.

\section{Procedures}

Following institutional ethical approval, participants were recruited online via the website of the magazine 'Runner's World'. Participants were asked to recall an important race in which they had competed during the last 4 weeks. A retrospective approach was used with participants recalling emotion regulation strategies used in the hour before competition. Ekman and Davidson (1994) suggested that people tend to remember emotionally charged events well, and retrospective measures of anxiety have been shown to be reliable up to 3 months after competition (Hanin \& Syrja, 1996).

\section{Data Analysis}

Confirmatory factor analysis (CFA) using EQS V6 (Bentler \& $\mathrm{Wu}, 1995)$ was used to test the hypothesized model. As there was evidence of multivariate non-normality in the data, models were tested using the Robust Maximum Likelihood method. This method has been found to effectively control for overestimation of $\mathrm{X}^{2}$, under-estimation of adjunct fit indexes, and under-identification of errors. The 2-factor measurement model for the EROS scale specified that each item related to its hypothesized factor with the variance of the factor fixed at 1 . Factors were allowed to freely inter-correlate. Model fit was judged acceptable if incremental fit indices were greater than .95 and the standardized Root Mean Error of Approximation (RMSEA) was lower than .08 (Hu \& Bentler, 1999).

\section{Results}

CFA results demonstrate that fit indices are marginally lower than values needed to be acceptable. The Robust Confirmatory 
Table 1.

Descriptive statistics and factor loadings for the emotion regulation of self scale in runners.

\begin{tabular}{|c|c|c|c|c|c|}
\hline Items & $M$ & $S D$ & Factor loading & Standarized Error & $\mathrm{R}^{2}$ \\
\hline \multicolumn{6}{|l|}{ Strategies to increase pleasant emotions } \\
\hline I laughed to try to improve how I felt & 2.96 & 1.97 & .42 & .91 & .18 \\
\hline I did something I enjoy to try to improve how I felt & 3.61 & 1.98 & .55 & .83 & .30 \\
\hline I sought support from others to try and make me feel better & 3.39 & 2.02 & .45 & .90 & .20 \\
\hline I thought about something nice to try and make me feel better & 4.05 & 1.87 & .83 & .561 & .69 \\
\hline I thought about positive aspects of my situation to try to improve how I felt & 4.63 & 1.74 & .76 & .65 & .58 \\
\hline I thought about my positive characteristics to try and make me feel better & 4.04 & 1.80 & .61 & .79 & .38 \\
\hline \multicolumn{6}{|l|}{ Strategies to increase unpleasant emotions } \\
\hline I started an argument with someone to try and make me feel worse & 1.15 & 0.64 & .39 & .92 & .15 \\
\hline I expressed cynicism to try and make me feel worse & 1.55 & 1.15 & .62 & .78 & .39 \\
\hline I listened to sad music to try and make me feel worse & 1.16 & 0.63 & .30 & .96 & .09 \\
\hline I looked for problems in my current situation to try to make me feel worse & 1.65 & 1.28 & .73 & .68 & .54 \\
\hline I thought about my shortcomings to try and make me feel worse & 1.69 & 1.28 & .78 & .62 & .61 \\
\hline I thought about negative experiences to try and make me feel worse & 1.53 & 1.15 & .68 & .73 & .47 \\
\hline
\end{tabular}

Fit Index, RCFI $=.92$, and the Non-Normed Fit Index NNFI $=.90$, were marginally lower than the .95 criterion proposed by Hu and Bentler (1995). The RMSEA (.07) was on the limit of acceptability. Factor loadings are contained in Table 1. As Table 1 indicates, weak factor loadings were found for the following items: "I laughed to try to improve how I felt", "I sought support from others to try and make me feel better ", "I started an argument with someone to try and make me feel worse", and "I listened to sad music to try and make me feel worse”. We removed 4 items and tested the 8 item and two-factor model. Results indicated improved fit indices (RCFI $=.97, \mathrm{NNFI}=.95$, RMSEA $=.06$ ) were acceptable according the criteria suggested by Hu and Bentler (1995).

\section{Discussion}

The aim of the present study was to extend the validation process of the emotion regulation of others and scale (Niven et al., 2011) for use in sport, namely running. Results of the present study provide some support for the validity of the scale. Acceptable fit indices (Hu \& Bentler, 1999) were found for a revised 8-item measure. However, despite these promising findings, concern is raised regarding the utility of some behavioral items. We propose that the shorter time frame used in the present study might explain why behavioral items showed poor factor loadings. Participants in the present study rated their use of emotion regulation strategies one hour before competition as opposed to over a 4 week period. However, in the hour before running competition, practical factors limit the possibility of using certain behavioral strategies. For example, it might not be possible to listen to music if athletes do not have access to a personal music player. We suggest the notion that athletes listen to music with a view to increase unpleasant emotions might be particularly problematic. Evidence suggest that an athlete who is attempting to self-regulate her emotions by listening to music tends to do so with a view to enhance performance (Bishop, Karageorghis, \& Loizou, 2007).

Given low factor loadings for behavioral items, we suggest that future researchers should develop items that are specific to the domain and timeframe under investigation. With reference to running, previous research has found that emotions in running associate with the relative difficulty of the self-set goal and the athlete's confidence to achieve this, the relative suitability of the course, and interactions with the coach (Jones, Swain, \& Cale, 1990; Lane, 2001). Studies have also suggested that runners cope with the demands of performance by focusing on the task at hand, for example concentrating on running technique (Stevinson \& Biddle, 1998) or on physical aspects of performance such as keeping their heart rate below a desired value, or focusing on distraction (Buman, Omli, Giacobbi, \& Brewer, 2008). We suggest that the emotion regulation scale should include additional behavioral items that focus on behavioral strategies focused on overcoming task demands (e.g., talking to runners who have completed the run, physically preparing for the run).

Given that evidence has demonstrated over 300 different strategies available (Augustine \& Hemenover, 2008), presenting this list to participants represents an impractical step forwards, particularly for applied research where brevity is an important issue. The number of strategies used is indicative of the ideographic nature of emotion regulation, and seeking to standardize or generalize these might result in a considerable loss of information. By developing items that cover generic categories of emotion regulation strategies it is argued that identification of commonly used strategies that individuals find effective could be obscured. For example, the growing use of transportable music devices has led to an increase in runners listening to music before and during running races. Therefore, we suggest that researchers should include open-ended questions to facilitate the ideographic nature of emotion regulation.

Continuing this line of research, we suggest future research 
should investigate the test-retest reliability of the scale. Although emotion regulation strategies have been proposed to be habitual (Wood, Quinn, \& Kashy, 2002), the extent to which they would be used in a specific situation will relate to emotional states. Emotions are transitory constructs and each competition carries a degree of uncertainty that will also tend to vary, and therefore, if regulatory efforts are needed before one particular race, but not before another, it is possible that test-retest relationships could be weak in cross-sectional studies. It is important to show that the scale has sufficient sensitivity, and that relationships between emotion and emotion regulation are invariant even if the relative frequency of usage and intensity of emotions changes.

In conclusion, we suggest that the emotion regulation scale shows a promising degree of validity for use in running. We suggest that future validation work should develop specific behavioral items for use in running.

\section{Acknowledgements}

The support of the Economic and Social Research Council (ESRC) UK is gratefully acknowledged (RES-060-25-0044: "Emotion regulation of others and self [EROS])".

\section{References}

Augustine, A. A., \& Hemenover, S. H. (2008). On the relative effectiveness of affect regulation strategies: A meta-analysis. Cognition \& Emotion, 23, 1181-1220. doi:10.1080/02699930802396556

Baumeister, R. F., Vohs, K. D., DeWall, C. N., \& Zhang, L. (2007). How emotion shapes behavior: Feedback, anticipation, and reflection, rather than direct causation. Personality and Social Psychology Review, 11, 167-203. doi:10.1177/1088868307301033

Beedie, C. J., Terry, P. C., \& Lane, A. M. (2000). The Profile of Mood States and athletic performance: two meta-analyses. Journal of Applied Sport Psychology, 12, 49-68. doi:10.1080/10413200008404213

Bentler, P. M., \& Wu, E. J. C. (1995). EQS/Windows user's guide. Los Angeles, CA: BMDP. Statistical Software.

Bishop, D. T., Karageorghis, C. I., \& Loizou, G. (2007). A grounded theory of young tennis players' use of music to manipulate emotional state. Journal of Sport \& Exercise Psychology, 29, 584-607.

Buman, M. P., Omli, J. W., Giacobbi, P. R., \& Brewer, B. W. (2008). Experiences and coping responses of hitting the wall for recreational marathon runners. Journal of Applied Sport Psychology, 20, 282-300. doi:10.1080/10413200802078267

Carver, C. S. (2004). Self-regulation of action and affect: New York: Guilford Press.

Cervone, D., Mor, N., Orom, H., Shadel, W. G., \& Scott, W. D. (2004). Self-efficacy beliefs on the architecture of personality: On knowledge, appraisal, and self-regulation. New York: Guilford Press.

Cronbach, L. J., \& Meehl, P. E. (1955). Construct validity in psychological tests. Psychological Bulletin, 52, 281-302. doi:10.1037/h0040957

Davies, K. A., Lane, A. M., \& Devonport, T. J. (2010). Validity and reliability of a Brief Emotional Intelligence Scale (BEIS-10). Journal of Individual Differences, 31, 198-208.

doi:10.1027/1614-0001/a000028

Dhingra, K. J., Totterdell, P., Tantam, D., \& Taylor, P. B. (2010). Emotion regulation in non-suicidal self injury. In J. Unwin (Ed.), Division of Clinical Psychology Conference (Vol. Leicester, pp. 56-57). The Lowry Hotel, Manchester: The British Psychological Society.

Duda, J. L. (1998). Advances in sport and exercise psychology measurement. Morgantown, United States: Fitness Information Technology, Inc.

Ekman, P., \& Davidson, R. J. (1994). The nature of emotion: Fundamental questions. Oxford: Oxford University Press.

Gould, D., \& Maynard, I. (2009). Psychological preparation for the Olympic Games. Journal of Sports Sciences, 27, 1393-1408. doi:10.1080/02640410903081845

Gross, J. J. (2007). Emotion regulation: Conceptual foundations. In J. J. Gross (Ed.), Handbook of Emotion Regulation. New York: Guilford.

Gross, J. J., \& John, O. P. (2003). Individual differences in two emotion regulation processes: Implications for affect, relationships, and well-being. Journal of Personality and Social Psychology, 85, 348362. doi:10.1037/0022-3514.85.2.348

Hanin, Y., \& Syrja, P. (1996). Predicted, actual, and recalled affect in Olympic-level soccer players: idiographic assessments on individualized scales. Journal of Sport \& Exercise Psychology, 18, 325-335.

Hanin, Y. L. (2003). Performance related emotional states in sport: A qualitative analysis.

http://www.qualitative-research.net/fqs-texte/1-03/1-03hanin-e.htm

Hu, L., \& Bentler, P. M. (1999). Cutoff criteria for fit indexes in covariance structure analysis: Conventional criteria versus new alternatives. Structural Equation Modeling, 6, 1-55. doi:10.1080/10705519909540118

Jokela, M., \& Hanin, Y. L. (1999). Does the individual zones of optimal functioning model discriminate between successful and less successful athletes: a meta-analysis. Journal of Sports Sciences, 17, 873-887. doi:10.1080/026404199365434

Jones, J. G., Swain, A., \& Cale, A. (1990). Antecedents of multidimensional competitive state anxiety and self-confidence in elite intercollegiate middle-distance runners. The Sport Psychologist, 4, 107-118.

Lane, A. M. (2001). Relationships between perceptions of performance expectations and mood among distance runners: the moderating effect of depressed mood. Journal of Science \& Medicine in Sport, 4, 116-128. doi:10.1016/S1440-2440(01)80013-X

Lane, A. M. (2007). Developing and validating Psychometric tests for use in high performance settings. In L. S. Boyar (Ed.), Psychological Tests and Testing Research (pp. 203-213). New York: Nova Publishers.

Larsen, R. (2009). The Contributions of positive and negative affect to emotional well-being. Psychological Topics, 18, 247-266.

Lazarus, R. S. (2000). How emotions influence performance in competitive sports. The Sport Psychologist, 14, 229-252.

Martin, L. L. (2001). Mood as input: A configural view of mood effects. Theories of mood and cognition: a users handbook, 135.

Nesse, R. M. (1990). Evolutionary explanations of emotions. Human Nature, 1, 261-289. doi:10.1007/BF02733986

Niven, K., \& Holman, D. (2009). Individual variability in interpersonal emotion regulation. Paper Presented at the British Psychological Society: Social Psychology Conference.

Niven, K., Totterdell, P., \& Holman, D. (2009). A classification of controlled interpersonal affect regulation strategies. Emotion, 9, 498-509. doi:10.1037/a0015962

Niven, K., Totterdell, P. A., Stride, C., \& Holman, D. (2011). Emotion Regulation of Others and Self (EROS): The development and validation of a new individual difference measure. Current Psychology, 30, 53-73. doi:10.1007/s12144-011-9099-9

Parkinson, B., \& Totterdell, P. (1999). Classifying affect-regulation strategies. Cognition and Emotion, 13, 277-303.

doi:10.1080/026999399379285

Pensgaard, A. M., \& Duda, J. L. (2003). Sydney 2000: The interplay between emotions, coping, and the performance of Olympic-level athletes. Sport Psychologist, 17, 253-267.

Robazza, C., Pellizzari, M., Bertollo, M., \& Hanin, Y. L. (2008). Functional impact of emotions on athletic performance: Comparing the IZOF model and the directional perception approach. Journal of Sports Sciences, 26, 1033-1047. doi:10.1080/02640410802027352

Schutz, R. W., \& Gessaroli, M. E. (1993). Use, misuse, and disuse of psychometrics in sport psychology research. Handbook of Research on Sport Psychology, 901-917.

Stevinson, C. D., \& Biddle, S. J. H. (1998). Cognitive orientations in marathon running and hitting the wall. British Journal of Sports Medicine, 32, 229-234. doi:10.1136/bjsm.32.3.229

Tamir, M. (2009). What Do People Want to Feel and Why? Current Directions in Psychological Science, 18, 101. doi:10.1111/j.1467-8721.2009.01617.x

Tamir, M., Chiu, C. Y., \& Gross, J. J. (2007). Business or pleasure? Utilitarian versus hedonic considerations in emotion regulation. Emotion, 7, 546-554. doi:10.1037/1528-3542.7.3.546

Tamir, M., Mitchell, C., \& Gross, J. J. (2008). Hedonic and instrumen- 
tal motives in anger regulation. Psychological Science, 19, 324. doi:10.1111/j.1467-9280.2008.02088.x

Tenenbaum, G., Edmonds, W. A., \& Eccles, D. W. (2008). Emotions, coping strategies, and performance: A conceptual framework for defining affect-related performance zones. Military Psychology, 20, S11-S37. doi:10.1080/08995600701804772

Terry, P. C., Lane, A. M., Lane, H. J., \& Keohane, L. (1999). Development and validation of a mood measure for adolescents. Journal of Sports Sciences, 17, 861-872. doi:10.1080/026404199365425

Thayer, R. E., Newman, J. R., \& McClain, T. M. (1994). Self-regulation of mood: Strategies for changing a bad mood, raising energy, and reducing tension. Journal of Personality and Social Psychology,
67, 910-910. doi:10.1037/0022-3514.67.5.910

Totterdell, P., \& Leach, D. (2001). Negative mood regulation expectancies and sports performance: an investigation involving professional cricketers. Psychology of Sport and Exercise, 2, 249-265.

doi:10.1016/S1469-0292(01)00016-4

Wallace, J. C., Edwards, B. D., Shull, A., \& Finch, D. M. (2009). Examining the consequences in the tendency to suppress and reappraise emotions on task-related job performance. Human Performance, 22, 23-43. doi:10.1080/08959280802540957

Wood, W., Quinn, J. M., \& Kashy, D. A. (2002). Habits in everyday life: Thought, emotion, and action. Journal of Personality and Social Psychology, 83, 1281-1297. doi:10.1037/0022-3514.83.6.1281 